DOI: 10.2478 /ausfm-2014-0016

\title{
Haptic Vision and the Experience of Difference in Agnès Varda's Les Glaneurs et la glaneuse (2000)
}

\author{
Romain Chareyron \\ University of Kansas \\ E-mail: romainchareyron@gmail.com
}

\begin{abstract}
This article investigates how, in her documentary The Gleaners and I (Les Glaneurs et la glaneuse, 2000), French director Agnès Varda relies on the establishment of haptic vision in order to merge the experience of her own body with the representation of another "body," that of people living at the margins of society and gleaning for food. In so doing, the article will bring out the director's social and aesthetic concerns by positing that Varda turns to a sensuous depiction based on the textural properties of the image to deter any form of instrumental vision regarding the representation of the body and its connections to pre-determined norms of conduct. The article will show that, in its portrayal of a socially and economically alienated group of people, as well as in the rendering of her aging body, Varda's miseen-scène brings forth a tactile form of knowledge that calls for a humanistic approach, thus defusing any form of mastery of the gaze over the image.
\end{abstract}

Keywords: Agnès Varda, The Gleaners and I, haptic vision, documentary.

It is with the advent of the DV camera that Agnès Varda had the idea for her acclaimed documentary The Gleaners and I. ${ }^{1}$ When it appeared in the mid-nineties, this type of handheld camera represented a new approach to filmmaking altogether, since its size and its technology allowed for a greater freedom on the director's part. Freed from the constraints of the traditional cinematic apparatus, the filmmaker could experience an unprecedented closeness to his or her subject as well as

1 Varda herself explains that the discovery of the digital camera was of paramount importance in her creative process and her desire to tackle the topic of gleaning: "There were three things [that interested her in filming the gleaners]. The first one was noticing the motion of these people bending in the open market. The second one was a program on TV. The third reason - which pushed me to begin and continue this film - was the discovery of the digital camera [...]. With the new digital camera, I felt I could find myself, get involved as a filmmaker.” (Anderson 2001, 24.) 
immediacy between themselves and the world they were recording on camera. These elements proved to be of the utmost interest for Varda, whose background in the still image and the theater has always driven her to explore the narrative and visual possibilities offered by the film medium. ${ }^{2}$ She then decided to embark on a journey across France in order to illustrate the different meanings the concept of "gleaning" covered in modern, consumerist French society (Vasse 2008, 190).

If, by recording the lives of people who glean as a means of survival or as a recreational hobby, Varda's primary intent is to offer a comment on French society at the dawn of the $21^{\text {st }}$ century, the significance of her documentary cannot be limited to its social and economic discourse, for it offers a more complex structure, both narratively and visually. Thanks to the handiness of the DV camera, Varda also "gleans" moments from her life, since she incorporates a series of shots of her own aging body throughout the documentary, when we see her filming her wrinkled hands in a close-up or brushing her greying hair, or else reenacting the act of gleaning. These images carve out a space within the documentary that allows the filmmaker's subjectivity to infuse the social discourse of the film, resulting in an aesthetic of collage which, Ágnes Pethő says, "amounts to a genuine collection of media representations and also offers an authentic record of the passion driving the filmmaker herself to collect and assemble and display the "booty' found in the world" (Pethô 2009, 53). The presence of such images blurs any pre-established boundary that might have defined the scope of the documentary, as the latter combines the objective task of filming poverty and social dismay and the more personal one of documenting Varda's own feelings regarding her body and the act of gleaning itself, in a fashion closely akin to the art of self-portrait. Varda herself points out to the kaleidoscopic nature of her documentary when she says: "I felt that although I'm not a gleaner - I'm not poor, I have enough to eat - there's another kind of gleaning, which is artistic gleaning. You pick ideas, you pick images, you pick emotions from other people, and then you make it into a film. Because I was also at a turn of age [...] I thought it should be mentioned somehow." (Anderson 2001, 24.) As a result, her documentary presents itself as an intricate piece of visual work whose initial

2 Varda first studied art history before shifting to photography, and she landed her first job as an official photographer for the Théâtre National Populaire (TNP) in Paris. She had little knowledge of film techniques and was quite inexperienced when she directed her first feature film, La Pointe Courte, in 1955. Richard Neupert points out to this fact when he writes: "Her background in art, literature, and theater was much stronger than her knowledge of film history or techniques [...]. Varda initially began filmmaking from a rather naïve perspective.” (Neupert 2002, 57.) 
endeavor is complicated by Varda's mise-en scène and the degree to which she blends seemingly heterogeneous elements within the film. ${ }^{3}$

However, what might first appear as a random assemblage of voices, places, and people actually proceeds from a thought-out humanistic and artistic undertaking on Varda's behalf. From a discursive perspective, the images that depict her filming her own body or reenacting the act of gleaning shall be considered as participating in the director's endeavor to deter any kind of hierarchy between the different social groups she records on camera. By choosing to shine a light on what is usually deemed as "improper" or "debasing" - the aging body or the act of gleaning - Varda favors fluidity, as her narrative is built around scenes that echo each other and call for an all-encompassing approach that bypasses socio-economic considerations. As Claude Murcia notes: "the mosaic structure and the absence of hierarchy it creates work to include marginalized and deprecated people within an 'egalitarian' and democratic patchwork: various types of outcasts stand alongside each other and are united by the film as being part of one large community defined by the act of gleaning" (Murcia 2009, 44 - my translation). From a visual perspective our main point of focus - the intimacy and proximity felt by the spectator, when confronted to the different bodily scenarios instated by Varda, redefine the scope of the traditional documentary film, ${ }^{4}$ as these images give rise to a form of knowledge that cannot be put into words, but only conveyed through a heightening of our senses by way of the textural properties of the image. ${ }^{5}$ Varda's filmic approach thus understands the act of gleaning as a social, political, and aesthetic gesture. In so doing, she privileges a visual regimen where the relationship between the spectator and the images is based on a tactile mode of apprehension rather than through mastery of the gaze. By resorting to the "mute" significance of images to convey a sense of contact between the spectator and the representation, Varda's mise-en-scène unearths the multi-layered meanings connected to the objects and bodies recorded on film in order to express their "non-reducible" qualities.

3 In his article Digression and return: Aesthetics and politics in Agnes Varda's Les Glaneurs et la glaneuse (2000), Ben Tyrer explores the complex narrative structure of the documentary and the blending of personal matters with political and economic considerations (Tyrer 2009, 161-176).

4 The questions of truthfulness and objectivity are the defining aspects of the documentary films. As William Guynn notes: "Documentary asserts the 'realism' of its discourse as against the imaginary world of fiction. The documentary film manifests the inherent relationship between cinematographic technology and the real; it assumes its 'natural' function in relation to its 'natural' object." (Guynn 1990, 19.)

5 To borrow from Claude Murcia, we could say that the documentary's reliance on nonverbal cues to generate meaning opens up a form of knowledge that exists outside of language ("en-deçà du langage et du sens"). (Murcia 2009, 46.) 
By showing what "gleaning" stands for in different social and historical contexts, Varda's initial will was to unveil the various meanings attached to this ancestral practice. What lies at the root of this undertaking is the acknowledgment that if in the past gleaning was a collaborative work that gathered people together, nowadays it is mostly endowed with negative connotations and stands for the dark side of capitalism and consumerist society. This contrast is made clear at the beginning of the documentary, through the iconography associated with the representation of these two periods of time. The first person interviewed, a middle-aged woman, recollects the time when, as a child, she went gleaning with the other women from her village. There is a strong sense of community and bonding that is expressed in her different memories of that time. Moreover, Varda connects these memories to images of paintings inspired by gleaning - the most famous of which being Francois Millet's The Gleaners (Les Glaneuses, 1857) - showing that, in the past, gleaning was considered a traditional aspect of rural life. The representation of gleaning in contemporary France that ensues acts as a stark counterpart to this somewhat idyllic depiction, as we see a series of shots representing people of all ages rummaging for food after a market day. The rap song that accompanies these shots reinforces the impressions of roughness and of social alienation that have come to qualify modern-day gleaning.

However, it would be wrong to see in the opposition of these two concepts a wish to conduct a didactic work of investigation. Instead, by confronting these two perceptions, Varda wants to bring out the shift in meaning that has been taking place over time regarding people's understanding of gleaning, and how we have come to perceive it in a unequivocal and negative light. In a similar way to what Jules Breton (The Gleaner [La Glaneuse], 1877) or Francois Millet achieved with their paintings, Varda uses art - here, cinema - to offer a reevaluation of this cultural and social practice by revealing what gleaning means to different groups of people. The director herself expresses her wish for a polyphonic approach when she says: "I think that documentary means 'real,' that you have to meet these real people, and let them express what they feel about the subject [...]. They make the statement; they explain the subject better than anybody. So it's not like having an idea about a subject and 'let's illustrate it.' It's meeting real people and discovering with them what they express about the subject, building the subject through real people.” (Anderson 2001, 25.)

With this documentary, Varda's goal is to avoid adopting a one-sided attitude when documenting the act of gleaning. To do so, she acknowledges the subjective part that lies at the heart of this practice: some people glean for survival, others for pleasure, and, for some, gleaning becomes part of a wider, artistic process. These 
varied attitudes towards gleaning create a mosaic of faces and voices that makes it impossible to restrict the meaning of the objects being gleaned, as they move from pure commodity to being the bearers of people's (hi)stories.

The scene that best illustrates this aspect of the documentary takes place when Varda films people gleaning potatoes after harvest time. This most common tuber comes to symbolize very different histories and memories for the people interviewed: for some, it represents an essential part of their diet, as gleaning provides them with their main source of food [Fig. 1]. For the people who work in a factory in charge of packaging potatoes, these vegetables constitute an item that has to be evaluated according to very specific criteria: if the potatoes do not correspond to the right caliber, or if they are green or damaged during the harvest, they are considered improper for retail and are then brought back to the fields to rot or be picked up by gleaners [Fig. 2]. Then, for Varda, the discovery of heartshaped potatoes offers the possibility to explore their textural qualities, as we see her gleaning potatoes and then filming them in a close-up that reveals the minute details of their cracked and dirty surface [Fig. 3, Fig. 4]. If the recourse to tactility is an aspect of the documentary we will deal with later on, it is possible to say that, in the scene we are analyzing now, this specific type of image works to extract the object of its traditional cultural environment to reveal aesthetic qualities that are commonly overlooked or ignored. These three different points of view serve to illustrate the director's intentions, that is, to reinstate the complexity of these objects and make it the heart of the narrative.

From this perspective, the social undertaking of Les Glaneurs... echoes Laura U. Marks's concept of "intercultural cinema," when she writes that "intercultural cinema moves through space, gathering up histories and memories that are lost or covered in the movement of displacement, and producing new knowledges out of the condition of being between cultures" (Marks 2000, 78). For Marks, intercultural films strive to expose the qualities that have been repressed or hidden in specific objects by the dominant culture. The aim of intercultural cinema is thus to unleash these qualities - or "radioactivity" - and make them the official discourse of the narrative: "they [intercultural films] may show how the meaning of an object changes as it circulates in new contexts. They may restore the 'radioactivity' of an object that has been sanitized or rendered inert through international trade. They may depict the object in such a way that it is protected from the fetishizing or commodifying gaze" (Marks 2000, 79).

This brings us back to the example of the potatoes; this humble food appears "re-endowed with history" (Marks 2000, 99) as the documentary focuses on the 
different values it acquires, moving from one cultural group to another. When Varda decides to film the heart-shaped potatoes in a close-up, not only does she attempt to bring forth a sense of touch within the narrative, she also wishes to focus on the different layers of significance and memories attached to this vegetable. The purpose of the DV camera is paramount in this sequence, as it allows Varda to create a specific kind of "relationship" between her and the objects which, in turns, enables the viewer to see and almost touch these objects in a way that a more traditional cinematic apparatus would not have made possible. It is by considering the body of the spectator as a complex surface with which the film image can interact, that Varda has created a documentary whose meaning does not so much arise from what is being shown as to how it is being shown, focusing on the complex and multi-layered realities encapsulated by the objects on screen. It does so by acknowledging the various identities that trivial objects can conceal but also, as we are going to observe now, by resorting to a particular form of contact between the spectator and the images.

Varda's wish to question perception and pre-established conceptions does not only apply to the objects being gleaned. Indeed, the director is seen shooting her wrinkled hands in a series of close-ups, and even extreme close-ups [Fig. 5], and we also see her combing her greying hair [Fig. 6], or else lying on a couch. The questions that emerge from these scenes concern the meaning that we ought to give these images as well as their larger significance within the documentary. At first sight, it seems quite problematic to assign them a clear narrative purpose; even though we come to understand that they are part of the filmmaker's project to "glean" memories and events through the use of the DV camera - the latter acting as a form of video diary - this explanation does not suffice to give coherence to the two discourses that structure the documentary. We have, on the one hand, a multi-faceted depiction of modern-day gleaning in France and, on the other hand, what could be considered as some sort of filmed autobiography. We need to focus on the quality of vision that Varda is establishing in these images as it is through a sensual appraisal of the film images that Varda intends to re-organize vision.

In these scenes the DV camera gives rise to a specific kind of image, where our attention is drawn to the materiality of the shot, more particularly, through a heightening of our sense of touch. The involvement of tactility as the main vehicle for perception is precisely what qualifies haptic vision since "whereas optic images set discrete, self-standing elements of figuration in illusionistic spaces, haptic images dehierarchize perception, drawing attention back to the tactile details and the material surface where figure and ground start to fuse" (Beugnet 2007, 
65-66). Haptic vision thus works as the "other side" of perception, giving way to a knowledge that is felt rather than thought. What it sought is a different kind of "being" in front of film images, where the spectator is physically aware of his or her body while sensually involved with(in) the fiction. That kind of involvement calls for a radically new approach to images, as they no longer appear to convey a single, pre-determined meaning or truth, but rather invite the viewer to experience the images through what I call "sensuous memory." What I mean here is that, whenever films resort to haptic vision, the viewer does not come into contact with the images using a set of external and pre-established concepts, but through personal affects and memories stored in his or her senses, and which the images activate by enhancing the textural qualities of the objects present on screen. ${ }^{6}$ In so doing, the film disrupts any attempt of a fetishizing look, as the viewer can only rely on his or her physical involvement to literally make sense of the images.

It is this unpredictability between the film and the viewer that rules Varda's mise-en-scène when we see her filming her own body, or as she reenacts the act of gleaning. Whenever the camera is letting our gaze linger on the spotted surface of her wrinkled hands or on the rough texture of potatoes being gleaned, the ideological barrier between the viewer and the cinematic space starts to waver. We are never put at a distance from the potatoes or from Varda's body, but are instead pulled towards them, as the evocative power of haptic vision asks us to emotionally invest the representation with the memories stored in our own sensations. Varda's mise-en-scène engages with the viewer on a deeply intimate level, as its emphasis on surfaces echoes personal and subjective experiences on the spectator's part. This closeness between the spectator and the images, combined with his or her physical and emotional involvement, make for an apprehension of the onscreen world that is removed from any external considerations. Haptic vision reaches for autonomic reactions manifested in the skin, thus opening new means of understanding and renewing cinema's pledge "to go beyond culturally prescribed limits and glimpse the possibility of being more than we are" (MacDougall 2005, 16).

$6 \quad$ As Laura U. Marks aptly points out, the focus on tactility, that emerges whenever haptic vision becomes the modus operandi of the mise-en-scène, does not necessarily aim at one specific organ on the viewer's body. Tactility can then generate bodily responses that are connected to other senses, thus triggering powerful memories stored in our sense of smell, our hearing or our vision: "Touch need not be linked explicitly to a single organ such as the skin but is enacted and felt throughout the body [...]. As a material mode of perception and expression, then, cinematic tactility occurs not only at the skin or the screen, but traverses all the organs of the spectator's body and the film's body" (Marks 2009, 2). 
In Varda's documentary, the physical involvement that is required by haptic vision also serves as a unifying device between the different discourses that constitute the narrative. Varda's documenting of her own body as well as of modern-day gleaning come together when analysed through the concept of haptic vision, as they offer a counter-discourse regarding utilitarian doctrines surrounding aging, poverty and mass consumption. We must now observe this more political statement through the film's tactile reenactment in order to understand "how [...] characters or the camera or the viewer perform particular kinds of touch, and what kinds of relationships among them do particular styles of touch imply?" (Barker 2009, 25). By resorting to haptic vision, Varda calls for a humanistic approach, asking us to feel things and understand them through a proprioceptive, non-judgmental approach. As our previous analyses tended to put forth, we do not stand as passive onlookers when we witness Varda filming her own body or gleaning food. We are instead drawn into the materiality of the film image so that we become the director's aging body, or the gleaners bending to the ground to reach food.

This idea of becoming the "Other" finds a visual translation within the documentary in the scenes where Varda, holding the DV camera with one hand, films her other hand. Two scenes are especially relevant; in the first one, we see her gleaning potatoes [Fig. 7], and in the second - one of the most striking scenes of the documentary - we see the camera tracking along her hand in an extreme close-up, so that at some point, we do not perceive a hand anymore, but a surface of veins and wrinkles, whose imperfections are heightened by the use of the chiaroscuro [Fig. 8]. This original use of the subjective camera - where the spectator is given the illusion of personal experience - is based on the conception of skin as "a meeting place for exchange and traversal because it connects the inside with the outside, the self with the other" (Barker 2009, 27). It is on the implications of such a carnal relationship between the viewer and the image that we need to focus on in order to understand how haptic vision is used to complicate the sense of touch and make the viewing experience one of mutual exchange and constant reevaluation.

For this contact to happen between the viewer and the film, an ideological shift needs to take place, where the projection screen is no longer perceived as a barrier between the spectator and the images, but rather as a membrane that allows interaction and reciprocity. If viewer and film are on an equal stage of footing, pre-conceived meanings do not take precedence over perception, allowing "the surface of the cinema screen [to] function[s] as an artificial organ of 
cognition. The prosthetic organ of the cinema screen does not merely duplicate cognitive perception, but changes its nature" (Buck-Morss 1994, 48). The use of haptic vision thus gives access to another dimension of perception, as it strives to create a continuum between the spectator and the images through a feeling of mutual recognition.

To express the kind of bond that seals this relationship, we wish to refer to Jennifer M. Barker's take on Merleau-Ponty's concept of "flesh" and its possible application in regards of the physical involvement that accompanies the filmviewing experience. For Merleau-Ponty, "flesh" is not restricted to the dermis that covers the body but also implies a mode of being based on the interdependency between human beings and the material world embraced by their field of vision. When applied to cinema, Barker argues, this concept allows for a "dialogue" between the spectator and the film, for neither of those instances stands above the other, but instead exist in a state of inclusion: “To apply Merleau-Ponty's concept of flesh to film theory is to contest the notion of either an ideal spectator, who accepts a meaning that is already intended by the film, or an empirical spectator, for whom the meaning of the film is determined solely by personal, cultural, and historical circumstances. Flesh insists on a spectator who is both at once, who joins the film in the act of making meaning." (Barker 2009, 26-27 - my emphasis.)

According to Barker, an exchange takes place between the spectator and the film whenever the mise-en-scène allows the symbolic barrier between the projection screen and the audience to become porous, so that the knowledge to be gained from the images is generated by a mutual impregnation between viewer and film. This sense of discovery through the image is the structuring device in the scene where Varda films her own hand. As she is scrutinizing her hand with the camera, she says "I mean this is my project: to film with one hand my other hand." As she comes closer to record the minutest details of her skin, she adds: "I feel as if I am an animal I don't know." What we are witnessing here is a (re)discovery of her own body by Varda through the technology of the DV camera, and her mixed feelings of amazement and horror at the sight of her own decaying flesh are powerful indicators of the renewal of meaning allowed by haptic vision.

The same process is at work in the scene where Varda films with one hand her other hand gleaning potatoes as she is bending to the ground, repeating the ancestral gesture that has been illustrated in many paintings and photographs. The shooting scale she uses whenever she films other people gleaning - mostly medium or long shots - no longer prevails when she is the one reenacting it. In 
a camera movement that mimics the gesture of the gleaner bending to pick up food, we see her hand reaching for potatoes and putting them into her satchel. Once again, the use of the subjective camera creates a higher degree of adherence between the spectator and the image so that we are no longer in a position to simply observe the onscreen world. We are physically engaged in the act of gleaning and the use of haptic vision, which allows us to feel the roughness of the potatoes' skin, conveys a sense of touch that takes precedence over any form of understanding. This tactile form of knowledge brings us back to what we discussed in the first part of our analysis; by filming herself gleaning potatoes and by emphasizing their textural qualities, Varda offers a social discourse that is not conveyed through words, but through the expression of the memories encoded in this vegetable. It is through haptic vision, and its ability to translate experiences that cannot be put into words, that the documentary becomes a repository of individual knowledge and defuses any form of instrumental vision. Gleaning is thus not perceived as a socially alienating act, since we are invited to "experience" it. Consequently, the images of gleaning are not just standing before our eyes, but are also moving us through a process by which "the viewer's skin extends beyond his or her own body; it reaches towards the film as the film reaches towards it" (Barker 2009, 33).

As this article tried to put forward, by choosing to make haptic vision the privileged mode of perception in specific sequences of the narrative, Varda makes her documentary a living and breathing entity, whose meaning is never set and well-defined, but evolves according to the "symbiosis" that takes place between the audience and the images. This relationship between viewer and film is conveyed by the nature of the images that unfold on the screen, and the bodily investment they require on the spectator's part. Varda's desire to reveal the multi-layered significance of the world she records on camera aims at offering a vision unencumbered with social and economic considerations. Her mise-en-scène asks us to engage in the fabric of the film and to experience the world it presents before our eyes. We enter the documentary the same way we would enter a dimly lit place: unsure of what lies ahead and relying on our senses to guide us through the unknown.

Varda's experimentations with the visual and narrative possibilities offered by the DV camera in Les Glaneurs... are in keeping with the unceasing desire to venture into uncharted filmic territories that influenced her entire career as a filmmaker. As Richard Neupert recalls: "Varda even coined the term cinécriture for her brand of filmmaking, which features carefully constructed image-to-sound 
textual relations" (Neupert 2002, 56). A pioneer of the French New Wave, Varda has always challenged traditional film techniques, and the documentaries she directed are no exception to the rule. ${ }^{7}$ Whether it be with L'Opéra-Mouffe (Diary of a Pregnant Woman, 1958), Documenteur (Mockumentary, 1982), Jane B. par Agnès V. (Jane B. by Agnès V., 1988) or, today, Les Glaneurs..., she has always considered the film image as a discursive tool whose meaning arises from the interaction between the filmmaker, the viewer, and the onscreen world. This lead her to come up with the term "subjective documentary" (Bluher 2009, 177) to define the particular relationship her works have with the concepts of "truth" and "reality" that traditionally shape our understanding of the genre.

When discussing nonfiction cinema, Marie-Jo Pierron-Moinel uses the concept of cinéma du regard ("cinema of the gaze") to define a type of documentary whose significance mainly arises from a sensitive and highly subjective appropriation of the onscreen world by the viewer. A similar kind of relationship between the audience and the representation is at work in Les Glaneurs..., as Varda's miseen-scène creates an intimate bond between the director, the viewer and the film image, making the documentary a journey of self-discovery rather than the neutral appraisal of social and economic realities. According to Pierron-Moinel, modern documentary is best understood as "a way of experiencing the world [that] sets itself up as a means of producing knowledge by combining sensations with understanding through one's gaze" (Pierron-Moinel 2010, 223 - my translation). By questioning our ritualized ways of experiencing the world, Varda asks us to reconsider our position as citizens but, more importantly, as living, breathing and feeling human beings. By creating a space where subjectivity and difference can be expressed freely, she points out to a form of knowledge that is not rooted in our intellect, but deep within our-selves.

7 By some aspects, the works of Agnès Varda are reminiscent of the aesthetic and narrative concerns of cinéma vérité in the way they both tackle the question of "reality" in film. An "offspring" of the New Wave when it appeared in France in the early 60's, cinéma vérité's main concern was to use film techniques to offer a representation that was a close as possible to life itself: "Cinéma vérité to its practitioners is a process of discovery - discovery of the truth [...]. In true cinema vérité filming, there is no formal plot, no preconceived dialogue, and, with few exceptions, no questions are either posed or answered by the filmmaker" (Issari and Paul 1979, 15). 


\section{References}

Anderson, Melissa. 2001. The Modest Gesture of the Filmmaker. An Interview with Agnès Varda. Cinéaste vol. 26 no. 4 (September): 24-27.

Barker, Jennifer M. 2009. The Tactile Eye: Touch and the Cinematic Experience. Berkeley and Los Angeles: University of California Press.

Beugnet, Martine. 2007. Cinema and Sensation: French Film and the Art of Transgression. Carbondale: Southern Illinois University Press.

Bluher, Dominique. 2009. La Miroitière. À propos de quelques films et installations d'Agnès Varda [About a Few Films and Installations of Agnès Varda]. In Agnès Varda: le cinema et au-delà [Agnès Varda: the Cinema and Beyond], eds. Antony Fiant and Éric Thouvenel, 177-185. Rennes: Presses universitaires de Rennes.

Bonner, Virginia. 2007. Beautiful Trash: Agnès Varda's Les Glaneurs et la glaneuse. Senses of Cinema. Issue 45 (November). http://www.sensesofcinema. com/2007/feature-articles/glaneurs-et-glaneuse/

Buck-Morss, Susan. 1998. The Cinema Screen as Prosthesis of Perception: A Historical Account. In The Senses Still: Perception and Memory as Material Culture in Modernity, ed. C. Nadia Seremetakis, 45-62. Chicago: University of Chicago Press.

Guynn, William. 1990. A Cinema of Nonfiction. London and Toronto: Associated University Presses.

Issari, M. Ali and Doris A. Paul. 1979. What is Cinéma Vérité? Metuchen, N.J.: The Scarecrow Press.

MacDougall, David. 2006. The Corporeal Image: Film, Ethnography, and the Senses. Princeton and Oxford: Princeton University Press.

Marks, Laura U. 2000. The Skin of the Film: Intercultural Cinema, Embodiment, and the Senses. Durham and London: Duke University Press.

Murcia, Claude. 2009. Soi et l'autre (Les Glaneurs et la glaneuse) [Self and Others (The Gleaners and I)]. In Agnès Varda: le cinema et au-delà [Agnès Varda: the Cinema and Beyond], eds. Antony Fiant and Éric Thouvenel, 43-48. Rennes: Presses universitaires de Rennes.

Neupert, Richard. 2002. A History of the French New Wave Cinema. Madison: The University of Wisconsin Press.

Pethő, Ágnes. 2009. (Re)Mediating the Real. Paradoxes of an Intermedial Cinema of Intimacy. Acta Univ. Sapientiae, Film and Media Studies no. 1: 47-68. 
Pierron-Moinel, Marie-Jo. 2010. Modernités et documentaires: Une mise en cause de la représentation [Modernities and Documentaries: A Challenge to Representation]. Paris: L'Harmattan.

Smith, Alison. 1998. Agnès Varda. Manchester and New York: Manchester University Press.

Tyrer, Ben. 2009. Digression and return: Aesthetics and politics in Agnès Varda's Les Glaneurs et la glaneuse (2000). Studies in French Cinema vol. 9 no. 2 (May): 161-176.

Vasse, David. 2008. Le Nouvel âge du cinéma d'auteur français [The New Age of French Auteur Cinema]. Paris: Klincksieck.

\section{List of Figures}

Figure 1. Gleaning for survival. Figure 2. A consumerist approach.
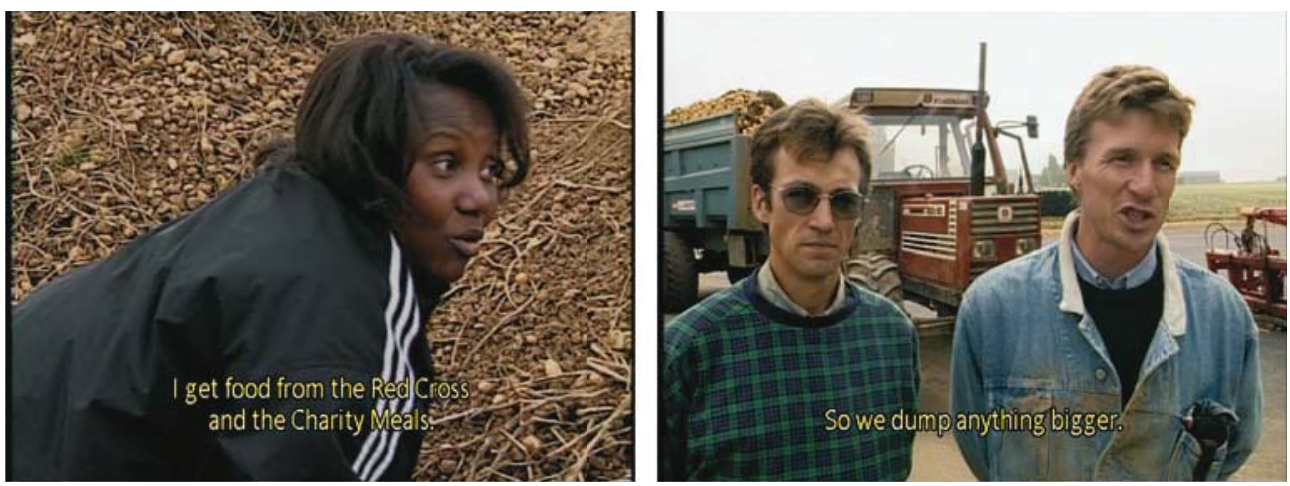

Figure 3. An artistic approach. Figure 4. Gleaning as an aesthetic gesture.
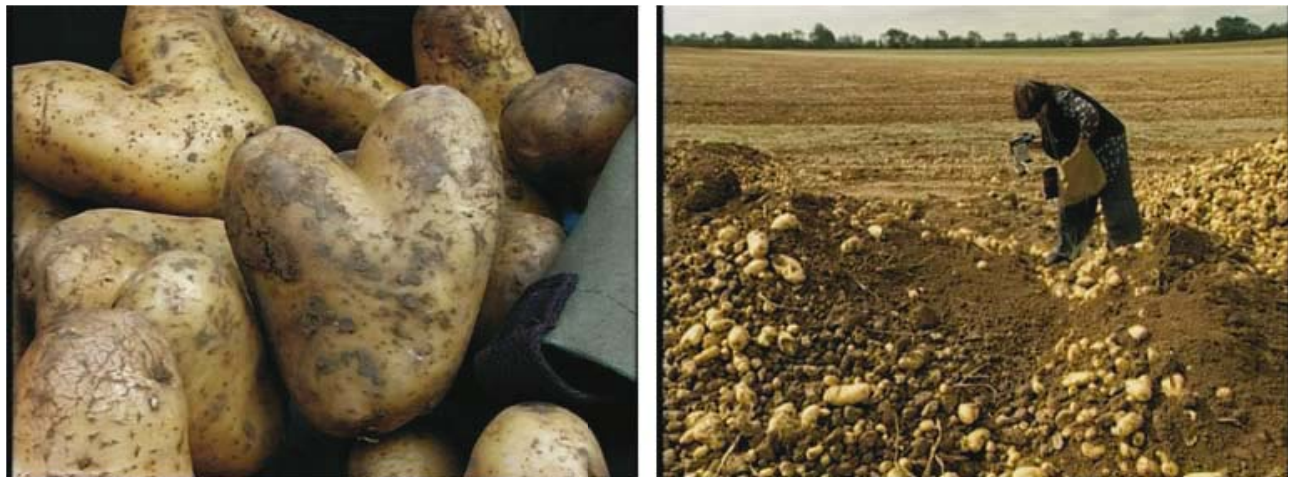
Figure 5. The DV camera and the emergence Figure 6. Blurring the social and the personal: of haptic vision. documenting the aging body.
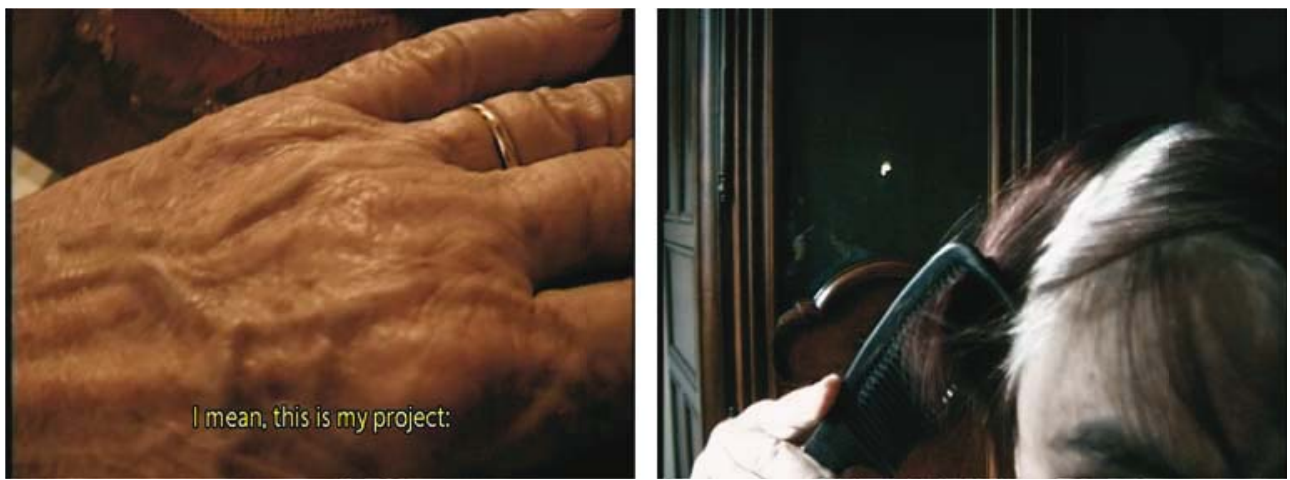

Figure 7. Reproducing the act of gleaning. Figure 8. The film image as a means of self-discovery.
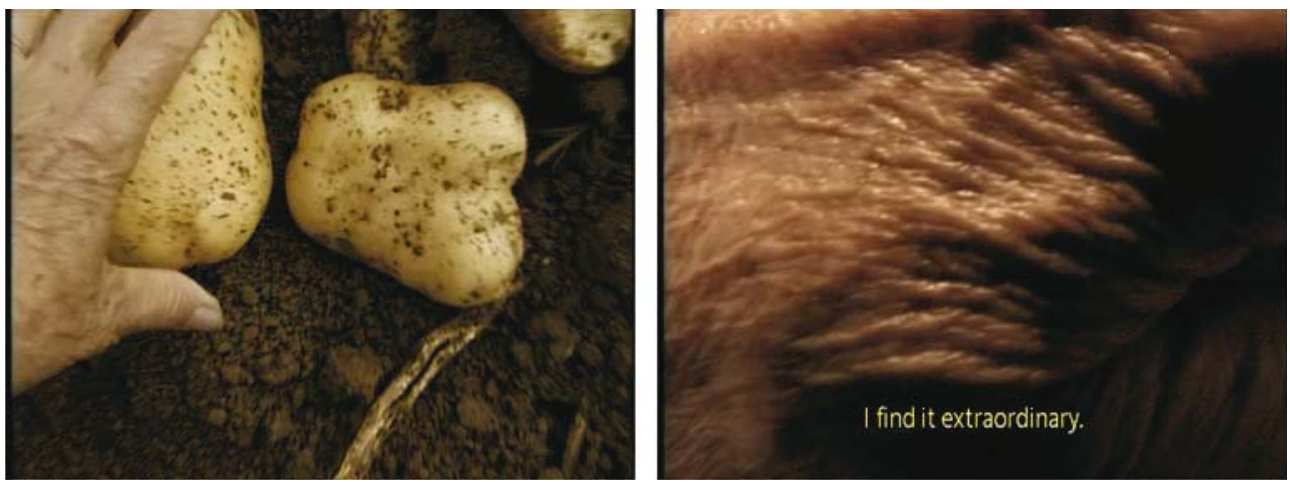